\title{
Free vibration analysis of axisymmetric laminated composite circular and annular plates using Chebyshev collocation
}

\author{
A. Powmya ${ }^{1}$ - M. C. Narasimhan ${ }^{2}$
}

Received: 10 January 2014/ Accepted: 6 April 2015/Published online: 23 April 2015

(c) The Author(s) 2015. This article is published with open access at Springerlink.com

\begin{abstract}
Solutions, based on principle of collocating the equations of motion at Chebyshev zeroes, are presented for the free vibration analysis of laminated, polar orthotropic, circular and annular plates. The analysis is restricted to axisymmetric free vibration of the plates and employs firstorder shear deformation theory for the displacement field, in terms of midplane displacements, $u, \alpha$ and $w$. The eigenvalue problem is defined in terms of three equations of motion in terms of the radial co-ordinate $r$, the radial variation of the displacements being represented in polynomial series, with appropriate boundary conditions. Numerical results are presented to show the validity and accuracy of the proposed method. Results of parametric studies for laminated polar orthotropic circular and annular plates with different boundary conditions, orthotropic ratios, lamination sequences, number of layers and shear deformation are also presented.
\end{abstract}

Keywords Free vibration - Chebyshev collocation method - First-order shear deformation theory .

Laminated composites

\section{List of symbols}

$\begin{array}{ll}r, \theta, z & \text { Cylindrical co-ordinates } \\ t & \text { Time }\end{array}$

A. Powmya

ampowmya@yahoo.co.in

M. C. Narasimhan

mattur.cn@gmail.com

1 Department of Built Environment Engineering, Muscat College, Muscat, Oman

2 Department of Civil Engineering, National Institute of Technology Karnataka, Mangalore, India
U

V

$W$

$\alpha_{1}$

$\alpha_{2}$

$\sigma_{r}, \sigma_{\theta}, \sigma_{z}$

$\tau_{r \theta}, \tau_{\theta z}, \tau_{r z}$

$\varepsilon_{r}, \varepsilon_{\theta}, \varepsilon_{z}$

$\gamma_{r \theta}, \gamma_{\theta z}, \gamma_{r z}$

$\varepsilon_{r}^{0}, \varepsilon_{\theta}^{0}, \gamma_{\mathrm{r} \theta}^{0}$

$\kappa_{r}, \kappa_{\theta}, \kappa_{r \theta}$

$C_{i j}$

$a, b$

h

Z

$N_{r}, N_{\theta}, N_{r \theta}$

$M_{r}, M_{\theta}, M_{r \theta}$

$Q_{r}, Q_{\theta}$

$A_{i j}$

$B_{i j}$

$D_{i j}$

N

$K^{2}$

$E_{r}, E_{\theta}$

$E, v$

D

$G_{r \theta}, G_{r z}$

$v_{r \theta}$

$n$
Inplane displacement in $r$ direction Inplane displacement in $\theta$ direction Inplane displacement in $z$ direction Rotation in $r$ direction

Rotation in $\theta$ direction

Normal stresses along principal material directions

Shear stresses along principal material directions

Normal strains along principal material directions

Shearing strains along principal material directions

Midplane strains of a laminate

Midplane curvatures of a laminate

Plane-stress reduced lamina stiffnesses

Outer and inner radii of the laminated plate

Total thickness of the laminate

Distance of lamina from midplane

Inplane mechanical stress resultants

Moment mechanical stress resultants

Transverse shear stress resultants

Extension stiffness

Bending-extension coupling stiffness

Bending stiffness

Number of collocation points

Shear correction factor

Modulus of elasticity

Young's modulus and Poisson's ratio of an isotropic material

Bending stiffness of an isotropic material

Shear modulus

Poisson's ratio of the plate material

Number of layers 


$\begin{array}{ll}\xi & \text { Nondimensional radial co-ordinate } \\ U, W, \alpha & \text { Nondimensional displacement components } \\ q & \text { Transverse load intensity } \\ p & \text { Nondimensional load intensity } \\ \rho & \text { Density } \\ \lambda & \text { Nondimensional frequency parameter } \\ \omega & \text { Axisymmetric frequency parameter } \\ C & \text { Clamped boundary condition } \\ S & \text { Simply supported boundary condition } \\ {[K],[M]} & \text { Stiffness and mass matrices of the laminate } \\ T_{r}(x) & r \text { th-order Chebyshev polynomial } \\ T_{r}^{*}(\xi) & \text { The shifted Chebyshev polynomial in the } \\ & \text { specified range }\end{array}$

\section{Introduction}

Fiber-reinforced composite structures are often subjected to dynamic loading caused by time-dependent loads causing vibrations or wave propagation. Then, the response of these structures under time-varying loads depends not only on the distribution of the stiffness of material in the structure, but also on the distribution of mass inertia. The analyst has to then consider the effect of inertia forces set up within the structure at any instant. The studies of flexural vibrations of plates subjected to different boundary conditions have thus received considerable interest because of their technological importance, and also give a good idea of response characteristics of the structure under dynamic loads.

Circular and annular plates are commonly used structural components in aerospace, civil, mechanical, electronic and nuclear engineering applications. In industrial situations, it is often required to predict the free vibration characteristics of these plates. For the free vibration analysis of various plates, there are a number of solution techniques, such as analytical methods, energy methods, finite difference methods and finite element methods. Analytical solutions form an important basis for comparison and verification of results obtained by numerical methods such as the finite element method. Among the different $m$ is also the Chebyshev collocation method.

There have been a number of investigations of the free vibration of homogeneous isotropic circular and annular plates such as Han and Liew (1999), Haterbouch and Benamar (2005), Liew et al. (1997), Liew and Yang (1999), Liew and Yang (2000), Selmane and Lakis (1999) and Zhou et al. (2003). There are works employing solutions using differential quadrature and generalized differential quadrature methods for the study of this class of problems and so also a few finite element solutions for the analysis of laminated plates and shells such as Han and Liew (1997), Lin and Tseng (1998), Ding and Xu (2000), Liew and Liu (2000), Wu et al. (2002), Tornabene et al. (2009) and Hosseini-Hashemi et al. (2010). In a recent paper (Xiang et al. 2014), the equations of motion of composite laminated annular plates, conical and cylindrical shells, with various boundary conditions based on the first-order shear deformation theory, have been solved for natural frequencies using an innovative, Haar wavelet discretization method. However, there are not many studies showing use of collocation at Chebyshev zeroes as an effective solution methodology for the determination of natural frequencies of laminated circular and annular plates.

In the present work, it is proposed to study the free vibration characteristics of laminated polar orthotropic circular and annular plates by Chebyshev collocation method. The possible application of orthogonal collocation to boundary value problems has been discussed by Villadsen and Stewart as early as (1967). Carey and Finlayson (1974) have explored the concept of orthogonal collocation in finite element analysis. The method has been used earlier for solving problems of free vibration analysis and large amplitude deflection analysis of isotropic and orthotropic spherical shells-static analysis (Dumir et al. 1984; Nath and Jain 1986). Dumir et al. (2001) have presented geometrically nonlinear analysis of a moderately thick, laminated composite annular plate subjected to uniformly distributed ring loads. Narasimhan (1992) has analyzed the problem of dynamic response analysis of laminated spherical shells using the same method. Herein, the possible application of the methodology for solution of axisymmetric free vibration response of circular and annular (polar) orthotropic plates has been illustrated.

In the present research, the reference plane displacements $u, \alpha$ and $w$ are expanded in polynomial series and then orthogonal point collocation method is used to discretise the governing equations. The eigenvalue problem is derived from the equations of motion, neglecting the rotary inertia and inplane inertia terms. To demonstrate the convergence of the method, numerical results are presented for clamped and simply supported isotropic and polar orthotropic circular and annular plates. The validity of the solution methodology adopted is confirmed by comparing nondimensional frequencies for isotropic and polar orthotropic plates obtained from the proposed solution with data obtained from open literature. It is observed that the present method is efficient in obtaining the free vibration frequencies and mode shapes of the laminated circular and annular plates made of composite materials. Parametric 
studies are also conducted and it is concluded that free vibration frequencies are dependent not only on the boundary conditions, but also on the parameters such as fiber orientation, lamination sequence and hole diameter.

\section{Methods}

\section{Mathematical formulation}

The laminated plate of constant thickness $h$ is composed of polar orthotropic laminae stacked in any arbitrary sequence, but with their fiber reinforcement aligned either in radial or circumferential directions only is considered. Polar co-ordinates $(r, \theta, z)$ are used for plate co-ordinates as shown in Fig. 1, where $u, v, w$ denote the displacements of any point of the plate in the corresponding $r, \theta, z$ directions.

First-order shear deformation theory is employed in the present study and the displacement field is assumed to be of the form

$$
\begin{aligned}
u(r, \theta, z) & =u^{0}(r, \theta)+z \alpha_{1}(r, \theta), \\
v(r, \theta, z) & =v^{0}(r, \theta)+z \alpha_{2}(r, \theta), \\
w(r, \theta, z) & =w^{0}(r, \theta)
\end{aligned}
$$

where $u^{0}, v^{0}, w^{0}$ denote the displacements of any point on the middle surface and $\alpha_{1}, \alpha_{2}$ are the rotations of the normal to the midplane about $\theta, r$ axes, respectively.

The linear strain displacement relations for the general motion of a point on the reference surface of laminated orthotropic circular plates are given by

$\varepsilon_{r}=\varepsilon_{r}^{0}+z \cdot \kappa_{r}, \quad \varepsilon_{\theta}=\varepsilon_{\theta}^{0}+z \cdot \kappa_{\theta}, \quad \gamma_{r \theta}=\gamma_{r \theta}^{0}+z \cdot \kappa_{r \theta}$,

$\gamma_{r z}=\gamma_{r z}^{0}, \quad \gamma_{\theta z}=\gamma_{\theta z}^{0}$

where the reference surface strains and curvatures are given by

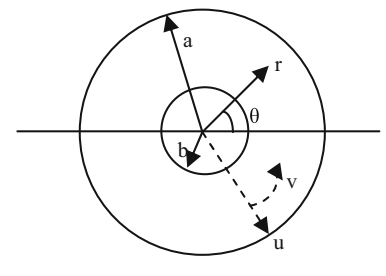

Plan

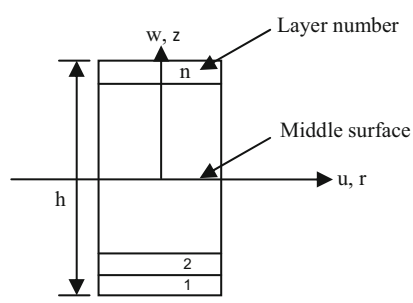

Section
Fig. 1 Geometry of $n$-layered laminate

$$
\begin{aligned}
\varepsilon_{r}^{0} & =\frac{\partial u^{0}}{\partial r}, \quad \varepsilon_{\theta}^{0}=\frac{1}{r} \cdot\left(\frac{\partial v^{0}}{\partial \theta}+u^{0}\right) \\
\gamma_{r \theta}^{0} & =\frac{1}{r} \cdot\left(\frac{\partial u^{0}}{\partial \theta}-v^{0}\right)+\frac{\partial v^{0}}{\partial r}, \\
\gamma_{r z}^{0} & =\alpha_{1}+\frac{\partial w}{\partial r}, \quad \gamma_{\theta z}^{0}=\alpha_{2}+\frac{1}{r} \cdot\left(\frac{\partial w}{\partial \theta}\right) \\
\kappa_{r} & =\frac{\partial \alpha_{1}}{\partial r}, \quad \kappa_{\theta}=\frac{1}{r} \cdot\left(\frac{\partial \alpha_{2}}{\partial \theta}+\alpha_{1}\right), \\
\kappa_{r \theta} & =\frac{1}{r} \cdot\left(\frac{\partial \alpha_{1}}{\partial \theta}-\alpha_{2}\right)+\frac{\partial \alpha_{2}}{\partial r}
\end{aligned}
$$

According to the shear deformation theory, the constitutive equations for the $k$ th layer of a polar orthotropic laminated plate can be written in the following form in polar co-ordinates

$$
\begin{aligned}
& \left\{\begin{array}{l}
\sigma_{r} \\
\sigma_{\theta} \\
\tau_{r \theta}
\end{array}\right\}^{(k)}=\left[\begin{array}{ccc}
C_{11} & C_{12} & 0 \\
C_{12} & C_{22} & 0 \\
0 & 0 & C_{66}
\end{array}\right]^{(k)}\left\{\begin{array}{l}
\varepsilon_{r} \\
\varepsilon_{\theta} \\
\gamma_{r \theta}
\end{array}\right\}, \\
& \left\{\begin{array}{l}
\tau_{r z} \\
\tau_{\theta z}
\end{array}\right\}^{(k)}=\left[\begin{array}{cc}
C_{44} & 0 \\
0 & C_{55}
\end{array}\right]^{(k)}\left\{\begin{array}{l}
\gamma_{r z} \\
\gamma_{\theta z}
\end{array}\right\}^{(k)},
\end{aligned}
$$

where the elastic constants are expressed in terms of material constants of the lamina in the plate co-ordinates as

$$
\begin{aligned}
& C_{11}=\frac{E_{r}}{1-v_{r \theta} v_{\theta r}} \quad C_{12}=\frac{v_{r \theta} E_{\theta}}{1-v_{r \theta} v_{\theta r}}=\frac{v_{\theta r} E_{r}}{1-v_{r \theta} v_{\theta r}} \\
& C_{22}=\frac{E_{\theta}}{1-v_{r \theta} v_{\theta r}} \\
& C_{44}=G_{r z}, \quad C_{55}=G_{\theta z}, \quad C_{66}=G_{r \theta}
\end{aligned}
$$

where $E_{r}$ and $E_{\theta}$ are Young's moduli of elasticity in $r$ and $\theta$ directions. $v_{r \theta}$ and $v_{\theta r}$ are Poisson's ratios. $G_{r \theta}, G_{\theta z}$ and $G_{r z}$ are the shear moduli in the respective planes.

The stress resultants acting on a laminate are obtained as:

$$
\begin{aligned}
{\left[\begin{array}{ll}
N_{r} & M_{r} \\
N_{\theta} & M_{\theta} \\
N_{r \theta} & M_{r \theta}
\end{array}\right] } & =\int_{-h / 2}^{h / 2}\left\{\begin{array}{c}
\sigma_{r} \\
\sigma_{\theta} \\
\tau_{r \theta}
\end{array}\right\}(1, z) \mathrm{d} z \\
& =\sum_{k=1}^{n} \int_{z_{k-1}}^{z_{k}}\left\{\begin{array}{c}
\sigma_{r} \\
\sigma_{\theta} \\
\tau_{r \theta}
\end{array}\right\}(1 z) \mathrm{d} z \\
\left\{\begin{array}{l}
Q_{r} \\
Q_{\theta}
\end{array}\right\} & =K^{2} \int_{-h / 2}^{h / 2}\left\{\begin{array}{l}
\tau_{r z} \\
\tau_{\theta z}
\end{array}\right\} \mathrm{d} z=K^{2} \sum_{k=1}^{n} \int_{z_{k-1}}^{z_{k}}\left\{\begin{array}{l}
\tau_{r z} \\
\tau_{\theta z}
\end{array}\right\}^{(k)} \mathrm{d} z
\end{aligned}
$$

where $z$ is the distance of the lamina from the middle plane. 
The first-order shear deformation theory used herein assumes a constant state of transverse shear strain through the thickness of the plate and hence requires shear correction factors introduced to account for non-uniform distribution of the transverse shear strains through the thickness of the plate. In Eq. (6), $K^{2}$ is the Shear correction factor introduced to account for non-uniform distribution of the transverse shear strains through the thickness of the plate, which is taken as $\pi^{2} / 12$.

Substituting the stress strain relations in the expressions for stress resultants, we have where, $A_{i j}=\sum_{k=1}^{n}\left(C_{i j}\right)^{(k)}\left(z_{k}-z_{k-1}\right), \quad i, j=1,2,6,4,5$

$B_{i j}=\frac{1}{2} \sum_{k=1}^{n}\left(C_{i j}\right)^{(k)}\left(z_{k}^{2}-z_{k-1}^{2}\right), \quad i, j=1,2,6$

$D_{i j}=\frac{1}{3} \sum_{k=1}^{n}\left(C_{i j}\right)^{(k)}\left(z_{k}^{3}-z_{k-1}^{3}\right), \quad i, j=1,2,6$

$A_{i j}$ is the extensional stiffness, $B_{i j}$ is the bending-extension coupling stiffness, $D_{i j}$ is the bending stiffness.

$$
\begin{aligned}
& \left\{\begin{array}{l}
N_{r} \\
N_{\theta} \\
N_{r \theta}
\end{array}\right\}=\sum_{k=1}^{n}\left[\begin{array}{ccc}
C_{11} & C_{12} & 0 \\
C_{12} & C_{22} & 0 \\
0 & 0 & C_{66}
\end{array}\right]^{(k)}\left\{\int_{z_{k-1}}^{z_{k}}\left\{\begin{array}{l}
\varepsilon_{r}^{\circ} \\
\vdots \\
\varepsilon_{\theta} \\
\gamma_{r \theta}
\end{array}\right\} \mathrm{d} z+\int_{z_{k-1}}^{z_{k}}\left\{\begin{array}{l}
\kappa_{r} \\
\kappa_{\theta} \\
\kappa_{r \theta}
\end{array}\right\} z \mathrm{~d} z\right\} \\
& \left\{\begin{array}{l}
M_{r} \\
M_{\theta} \\
M_{r \theta}
\end{array}\right\}=\sum_{k=1}^{n}\left[\begin{array}{ccc}
C_{11} & C_{12} & 0 \\
C_{12} & C_{22} & 0 \\
0 & 0 & C_{66}
\end{array}\right]^{(k)}\left\{\int_{z_{k-1}}^{z_{k}}\left\{\begin{array}{l}
\varepsilon_{r}^{\circ} \\
\varepsilon_{\theta} \\
\varepsilon_{r \theta}^{\circ}
\end{array}\right\} z \mathrm{~d} z+\int_{z_{k-1}}^{z_{k}}\left\{\begin{array}{l}
\kappa_{r} \\
\kappa_{\theta} \\
\kappa_{r \theta}
\end{array}\right\} z^{2} \mathrm{~d} z\right\} \\
& \left\{\begin{array}{l}
Q_{r} \\
Q_{\theta}
\end{array}\right\}=K^{2} \sum_{k=1}^{n}\left[\begin{array}{cc}
C_{44} & 0 \\
0 & C_{55}
\end{array}\right]^{(k)}\left\{\int_{z_{k-1}}^{z_{k}}\left\{\begin{array}{l}
\gamma_{r z} \\
\gamma_{\theta z}
\end{array}\right\} \mathrm{d} z\right\} .
\end{aligned}
$$

Since $\varepsilon_{r}^{0}, \varepsilon_{\theta}^{0}, \gamma_{r \theta}^{0}, \kappa_{r}, \kappa_{\theta}, \kappa_{r \theta}, \gamma_{r z}^{0}, \gamma_{\theta z}^{0}$ are middle surface strains and curvatures and not functions of $z$, they can be taken out of the integration signs. Thus, the total plate constitutive equations can be written as
If the plates are subjected to transverse loads only, the stress resultants and stress couples must satisfy the following equilibrium equations (Ravichandran 1989)

$$
\left\{\begin{array}{l}
N_{r} \\
N_{\theta} \\
N_{r \theta} \\
M_{r} \\
M_{\theta} \\
M_{r \theta} \\
Q_{r} \\
Q_{\theta}
\end{array}\right\}=\left[\begin{array}{cccccccc}
A_{11} & A_{12} & 0 & B_{11} & B_{12} & 0 & 0 & 0 \\
A_{12} & A_{22} & 0 & B_{12} & B_{22} & 0 & 0 & 0 \\
0 & 0 & A_{66} & 0 & 0 & B_{66} & 0 & 0 \\
B_{11} & B_{12} & 0 & D_{11} & D_{12} & 0 & 0 & 0 \\
B_{12} & B_{22} & 0 & D_{12} & D_{22} & 0 & 0 & 0 \\
0 & 0 & B_{66} & 0 & 0 & D_{66} & 0 & 0 \\
0 & 0 & 0 & 0 & 0 & 0 & K^{2} A_{44} & 0 \\
0 & 0 & 0 & 0 & 0 & 0 & 0 & K^{2} A_{55}
\end{array}\right]\left\{\begin{array}{l}
\varepsilon_{r}^{\circ} \\
\varepsilon_{\theta} \\
\gamma_{r \theta}^{\circ} \\
\kappa_{r} \\
\kappa_{\theta} \\
\kappa_{r \theta} \\
\gamma_{r z}^{\circ} \\
\gamma_{\theta z}^{\circ}
\end{array}\right\}
$$




$$
\begin{aligned}
& \frac{\partial N_{r}}{\partial r}+\frac{1}{r} \frac{\partial N_{r \theta}}{\partial \theta}+\frac{\left(N_{r}-N_{\theta}\right)}{r}=0 \\
& \frac{\partial Q_{r}}{\partial r}+\frac{1}{r} \frac{\partial Q_{\theta}}{\partial \theta}+\frac{Q_{r}}{r}=I_{o} \frac{\partial^{2} w}{\partial t^{2}}, \frac{\partial M_{r}}{\partial r} \\
& \quad+\frac{1}{r} \frac{\partial M_{r \theta}}{\partial \theta}+\frac{\left(M_{r}-M_{\theta}\right)}{r}=Q_{r} \\
& \frac{\partial N_{r \theta}}{\partial r}+\frac{1}{r} \frac{\partial N_{\theta}}{\partial \theta}+2 \frac{N_{r \theta}}{r}=0, \quad \frac{\partial M_{r \theta}}{\partial r}+\frac{1}{r} \frac{\partial M_{\theta}}{\partial \theta}+2 \frac{M_{r \theta}}{r}=Q_{\theta}
\end{aligned}
$$

where $I_{0}=\sum_{k=1}^{n} \int_{h_{k-1}}^{h_{k}} \rho^{(k)} d z$

$$
=\rho h \sum_{k=1}^{n}\left\{\frac{\rho^{(k)}}{\rho h}\left(h_{k}-h_{k-1}\right)\right\}=\rho h R_{m}
$$

where $R_{m}=\sum_{k=1}^{n}\left\{\frac{\rho^{(k)}}{\rho h}\left(h_{k}-h_{k-1}\right)\right\}$

and $\rho$ is a reference density.

For axisymmetric case, the stresses and strains are independent of $\theta$ and $\tau_{r \theta}=\tau_{z \theta}=0, v^{0}=0, \alpha_{2}=0$ and also $\frac{\partial}{\partial \theta}()=0$. This also leads to $N_{r \theta}=0, M_{r \theta}=0$ and $Q_{\theta}=0$.

Substituting for stress resultants and stress couples in Eq. (10) in terms of strains and curvatures which in turn are substituted in terms of displacements given by Eq. (3), the equations take the form

$$
\begin{aligned}
& A_{11}\left(\frac{\partial^{2} u^{0}}{\partial r^{2}}+\frac{\partial u^{0}}{r \cdot \partial r}\right)-A_{22} \frac{u^{0}}{r^{2}}+B_{11}\left(\frac{\partial^{2} \alpha_{1}}{\partial r^{2}}+\frac{\partial \alpha_{1}}{r \cdot \partial r}\right) \\
& -B_{22} \frac{\alpha_{1}}{r^{2}}=0 \\
& B_{11}\left(\frac{\partial^{2} u^{0}}{\partial r^{2}}+\frac{\partial u^{0}}{r \cdot \partial r}\right)-B_{22} \frac{u^{0}}{r^{2}}+D_{11}\left(\frac{\partial^{2} \alpha_{1}}{\partial r^{2}}+\frac{\partial \alpha_{1}}{r \cdot \partial r}\right) \\
& -D_{22} \frac{\alpha_{1}}{r^{2}}=K^{2} A_{44}\left(\alpha_{1}+\frac{\partial w}{\partial r}\right) \\
& K^{2} A_{44}\left(\frac{\partial \alpha_{1}}{\partial r}+\frac{\alpha_{1}}{r}+\frac{\partial^{2} w}{\partial r^{2}}+\frac{\partial w}{r \cdot \partial r}\right)=I_{0} \frac{\partial^{2} w}{\partial t^{2}} .
\end{aligned}
$$

The following dimensionless parameters are introduced for convenience

$$
\begin{aligned}
U & =\frac{u^{0} \cdot(a-b)}{h^{2}}, \quad W=\frac{w^{0}}{h}, \quad \alpha=\frac{\alpha_{1} \cdot(a-b)}{h}, \\
\xi & =\frac{r-b}{a-b}, \quad p=\frac{q \cdot(a-b)^{4}}{E_{T} \cdot h^{4}}, \\
a_{44} & =\frac{K^{2} \cdot A_{44}}{E_{T} \cdot h}, \quad b_{i j}=\frac{B_{i j}}{E_{T} \cdot h^{2}}, \quad d_{i j}=\frac{D_{i j}}{E_{T} \cdot h^{3}} .
\end{aligned}
$$

Here, $E_{T}$ is the reference Young's modulus. In case of laminated composites with layers of same material, $E_{T}$ can be taken conveniently to be the Young's modulus in the direction transverse to fiber direction.

Using the nondimensional quantities defined in (13), a set of equations of motion can now be written as

$$
\begin{aligned}
& a_{11}\left(\frac{1}{(a-b)^{2}} \cdot \frac{\partial^{2} U}{\partial \xi^{2}}+\frac{1}{(\xi a+(1-\xi) b) *(a-b)} \cdot \frac{\partial U}{\partial \xi}\right) \\
& \quad-a_{22} \frac{U}{(\xi a+(1-\xi) b)^{2}} \\
& \quad+b_{11}\left(\frac{1}{(a-b)^{2}} \cdot \frac{\partial^{2} \alpha}{\partial \xi^{2}}+\frac{1}{(\xi a+(1-\xi) b) *(a-b)} \cdot \frac{\partial \alpha}{\partial \xi}\right) \\
& \quad-b_{22} \frac{\alpha}{(\xi a+(1-\xi) b)^{2}}=0 \\
& \quad-\quad \frac{1}{\left.(a-b)^{2} \cdot \frac{\partial^{2} U}{\partial \xi^{2}}+\frac{U}{(\xi a+(1-\xi) b) *(a-b)} \cdot \frac{\partial U}{\partial \xi}\right)} \\
& \quad-b_{22} \frac{U}{(\xi a+(1-\xi) b)^{2}} \\
& +d_{11}\left(\frac{1}{(a-b)^{2}} \cdot \frac{\partial^{2} \alpha}{\partial \xi^{2}}+\frac{1}{(\xi a+(1-\xi) b) *(a-b)} \cdot \frac{\partial \alpha}{\partial \xi}\right) \\
& \quad-d_{22} \frac{\alpha}{(\xi a+(1-\xi) b)^{2}}=\frac{a_{44}}{h^{2}}\left(\alpha+\frac{\partial W}{\partial \xi}\right) \\
& a_{44} E_{T} h^{2}\left(\frac{1}{(a-b)} \cdot \frac{\partial \alpha}{\partial \xi}+\frac{\alpha}{(\xi a+(1-\xi) b)}+\frac{1}{(a-b)} \cdot \frac{\partial^{2} W}{\partial \xi^{2}}\right.
\end{aligned}
$$

\section{Polynomial series solution by collocation at Chebyshev zeroes}

To set up the eigenvalue problem for determination of free vibration frequencies and the corresponding mode shapes, 
in the present work, Chebyshev collocation method is used. The dependent variables $U, \alpha$ and $W$ and their derivatives are expressed in Chebyshev series as

$$
\{U(\xi, t), \alpha(\xi, t), W(\xi, t)\}=\left\{\sum_{n=1}^{N+1}\left(U_{n}, \alpha_{n}, W_{n}\right) \xi^{n-1}\right\} e^{i \omega t} .
$$

Using Eq. (15) the equations of motion can now be written as

$$
\begin{aligned}
& a_{11} \sum_{n=1}^{N+1}\left(\frac{(n-1)(n-2) U_{n} \xi^{n-3}}{(a-b)^{2}}+\frac{(n-1) U_{n} \xi^{n-2}}{(\xi a+(1-\xi) b) *(a-b)}\right) \\
& -a_{22} \sum_{n=1}^{N+1} \frac{U_{n} \xi^{n-1}}{(\xi a+(1-\xi) b)^{2}}+ \\
& b_{11} \sum_{n=1}^{N+1}\left(\frac{(n-1)(n-2) \alpha_{n} \xi^{n-3}}{(a-b)^{2}}+\frac{(n-1) \alpha_{n} \xi^{n-2}}{(\xi a+(1-\xi) b) *(a-b)}\right) \\
& -b_{22} \sum_{n=1}^{N+1} \frac{\alpha_{n} \xi^{n-1}}{(\xi a+(1-\xi) b)^{2}}=0 \\
& b_{11} \sum_{n=1}^{N+1}\left(\frac{(n-1)(n-2) U_{n} \xi^{n-3}}{(a-b)^{2}}+\frac{(n-1) U_{n} \xi^{n-2}}{(\xi a+(1-\xi) b) *(a-b)}\right) \\
& -b_{22} \sum_{n=1}^{N+1} \frac{U_{n} \xi^{n-1}}{(\xi a+(1-\xi) b)^{2}}+ \\
& d_{11} \sum_{n=1}^{N+1}\left(\frac{(n-1)(n-2) \alpha_{n} \xi^{n-3}}{(a-b)^{2}}+\frac{(n-1) \alpha_{n} \xi^{n-2}}{(\xi a+(1-\xi) b) *(a-b)}\right) \\
& -d_{22} \sum_{n=1}^{N+1} \frac{\alpha_{n} \xi^{n-1}}{(\xi a+(1-\xi) b)^{2}} \\
& +\frac{a_{44}}{h^{2}} \sum_{n=1}^{N+1}\left(\alpha_{n} \xi^{n-1}+(n-1) W_{n} \xi^{n-2}\right)=0 \\
& \frac{a_{44} \cdot a^{4}}{(a-b) d 11 \cdot h^{2}} \sum_{n=1}^{N+1}\left(\frac{(n-1) \alpha_{n} \xi^{n-2}}{(a-b)}+\cdot \frac{\alpha_{n} \xi^{n-1}}{(\xi a+(1-\xi) b)}\right. \\
& \left.+1)(n-2) W_{n} \xi^{n-3}+\frac{(n-1) W_{n} \xi^{n-2}}{(\xi a+(1-\xi) b)}\right)=-\lambda^{2} \sum_{n=1}^{N+1} W_{n} \xi^{n-1} \\
& (a-b)
\end{aligned}
$$

where $\lambda=\omega a^{2} \sqrt{\rho h / D_{11}}$.

Boundary conditions considered: The following combinations of boundary conditions have been considered in the present work.

Clamped boundary condition

At outer boundary $r=a, \quad u^{0}=\alpha_{1}^{0}=w^{0}=0$

for both circular plate and annular plate.

At inner boundary $r=b$,

$$
\begin{array}{cc}
u^{0}=\alpha_{1}^{0}=\mathrm{d} w^{0} / \mathrm{d} r=0 & \text { for circular plates and } \\
u^{0}=\alpha_{1}^{0}=w^{0}=0 & \text { for annular plates. }
\end{array}
$$

\section{Simply supported condition type}

At outer boundary $r=a, \quad u^{0}=M_{r}=w^{0}=0$

for both circular plate and annular plate.

At inner boundary $r=b$,

$$
\begin{array}{cc}
u^{0}=\alpha_{1}^{0}=\mathrm{d} w^{0} / \mathrm{d} r=0 & \text { for circular plates and } \\
u^{0}=M_{r}=w^{0}=0 & \text { for annular plates. }
\end{array}
$$

\section{Simply supported condition type}

At outer boundary $r=a, \quad N_{r}=M_{r}=w^{0}=0$

for both circular plate and annular plate.

At inner boundary $r=b$,

$$
\begin{array}{cc}
u^{0}=\alpha_{1}^{0}=\mathrm{d} w^{0} / \mathrm{d} r=0 & \text { for circular plates and } \\
N_{r}=M_{r}=w^{0}=0 & \text { for annular plates. }
\end{array}
$$

The $N$ th-degree Chebyshev polynomial $T_{N}^{*}$ has $N$ zeroes at

$\xi_{i}=\frac{1}{2}\left\{1+\cos \left[\frac{(2 * i-1) \pi}{2 N}\right]\right\} \quad i=1,2, \ldots, N$.

By forcing the satisfaction of each of the three differential equations at the $(N-1)$ zeroes of $T_{(N-1)}^{*}(\xi)$, $0 \leq \xi \leq 1-$ the $(N-1)$ th degree shifted Chebyshev Polynomial, along with the stipulation of the three boundary conditions at each edge the dynamic equilibrium equations, can be expressed by a set of algebraic equations as

$$
\begin{aligned}
& {\left[L_{11}\right]\{U\}+\left[L_{12}\right]\{\alpha\}+\left[L_{13}\right]\{q\}+\left[L_{14}\right]\{W\}=\{0\}} \\
& {\left[L_{21}\right]\{U\}+\left[L_{22}\right]\{\alpha\}+\left[L_{23}\right]\{q\}+\left[L_{24}\right]\{W\}=\{0\}} \\
& {\left[L_{31}\right]\{U\}+\left[L_{32}\right]\{\alpha\}+\left[L_{33}\right]\{q\}+\left[L_{34}\right]\{W\}} \\
& \quad=-\lambda^{2}[M]\{W\}
\end{aligned}
$$

where $\{U\},\{\alpha\},\{q\}$ and $\{W\}$ are the vectors containing the unknown coefficients which are defined by following equations

$$
\{U\}^{T}=\left\{U_{1}, U_{2}, \ldots, U_{n+1}\right\},
$$

Table 1 Free vibration frequencies of isotropic circular plate for convergence study

\begin{tabular}{lllll}
\hline$v=0.3$, boundary condition: clamped \\
\hline Number of terms & \multicolumn{4}{l}{ Frequency parameter $\lambda=\omega a^{2} \sqrt{\rho h / D}$} \\
\cline { 2 - 5 } & 1 & 2 & 3 & 4 \\
\hline 8 & 10.007 & 37.518 & 80.288 & 141.926 \\
10 & 10.007 & 37.514 & 79.617 & 132.955 \\
12 & 10.007 & 37.514 & 79.617 & 132.568
\end{tabular}


Table 2 Fundamental natural frequencies of clamped isotropic circular plates

\begin{tabular}{lllll}
\hline$\lambda=\omega a^{2} \sqrt{\rho h / D}, v=0.3$ & & \\
\hline$h / a$ & Present (FSDT) & Lin and Tseng (1998) (FSDT) & Liew et al. (1997) (FSDT) & Liew and Yang (1999) (3D) \\
\hline 0.05 & 10.153 & 10.047 & 10.145 & - \\
0.10 & 10.007 & 9.812 & 9.941 & 9.991 \\
0.15 & 9.764 & 9.453 & 9.628 & - \\
0.20 & 9.450 & 9.016 & 9.240 & 9.322 \\
0.3 & 8.703 & - & - & 8.467 \\
0.4 & 7.905 & - & - & 7.600 \\
0.5 & 7.124 & - & - & 6.807
\end{tabular}

Table 3 Fundamental natural frequencies of clampedclamped isotropic annular plate

\begin{tabular}{lrlll}
\hline \multicolumn{2}{l}{$\lambda=\omega a^{2} \sqrt{\rho h / D}, v=0.3$} & \\
\hline$b / a$ & $a / h$ & Present (FSDT) & Lin and Tseng (1998) (FSDT) & Han and Liew (1999) (FSDT) \\
\hline 0.1 & 10 & 25.116 & 24.480 & 24.629 \\
& 40 & 27.135 & 27.466 & - \\
& 100 & 27.241 & 27.585 & - \\
0.3 & 10 & 40.455 & 38.621 & 39.398 \\
& 40 & 44.982 & 45.143 & - \\
& 100 & 45.127 & 45.406 & - \\
0.5 & 10 & 73.192 & 67.934 & - \\
& 40 & 87.931 & 88.069 & -
\end{tabular}

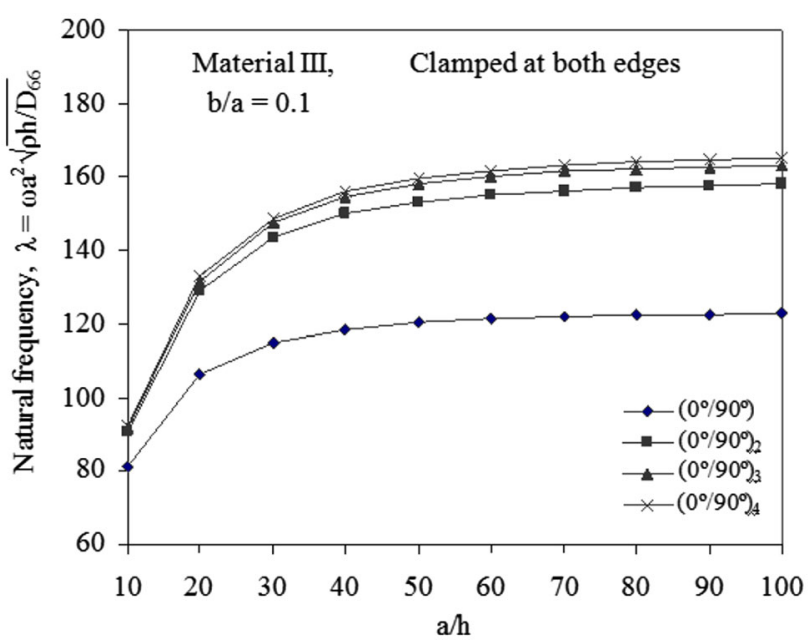

Fig. 2 Effect of number of layers on fundamental natural frequencies of laminated polar orthotropic annular plates

$\{\alpha\}^{T}=\left\{\alpha_{1}, \alpha_{2}, \ldots, \alpha_{n+1}\right\}$,

$\{q\}^{T}=\left\{W_{1}, W_{2}\right\}$

$\{W\}^{T}=\left\{W_{3}, W_{4}, \ldots, W_{n+1}\right\}$.
The Eq. (21) can be written together in matrix form as $\left[\begin{array}{ll}{\left[\bar{L}_{11}\right]} & {\left[\bar{L}_{12}\right]} \\ {\left[\bar{L}_{21}\right]} & {\left[\bar{L}_{22}\right]}\end{array}\right]\left\{\begin{array}{l}\{x\} \\ \{y\}\end{array}\right\}=\lambda^{2}\left[\begin{array}{cc}0 & 0 \\ {\left[\bar{M}_{21}\right]} & {\left[\bar{M}_{22}\right]}\end{array}\right]\left\{\begin{array}{l}\{x\} \\ \{y\}\end{array}\right\}$

where $\{x\}^{T}=\left\{\{U\}^{T}\{\alpha\}^{T}\{q\}^{T}\right\},\{y\}^{T}=\{W\}^{T}$.

By matrix condensation, Eq. (23) can be rewritten as

$[\bar{K}]\{y\}=\lambda^{2}[\bar{M}]\{y\}$.

The solution of the above eigenvalue problem leads to the determination of the natural frequencies and mode shapes of the laminated orthotropic circular and annular plates undergoing axisymmetric vibrations.

\section{Results and discussion}

A C-program developed by Antia (2002) is used in the present work for the free vibration analysis of laminated polar orthotropic circular and annular plates based on the solution methodology described in the preceding sections. Convergence and comparison studies were made to establish the validity of the method. Results of parametric 


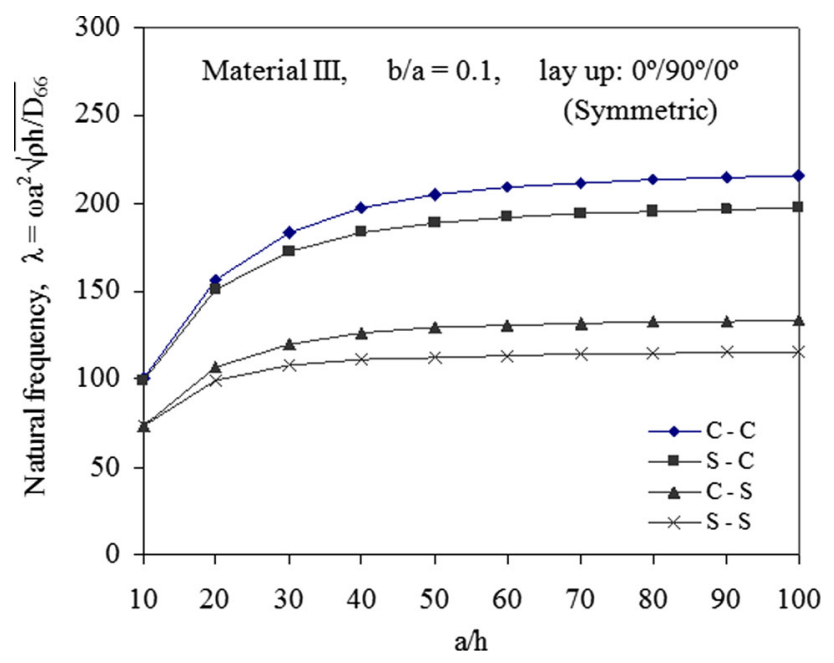

Fig. 3 Effect of boundary conditions on fundamental natural frequencies of laminated polar orthotopic annular plates

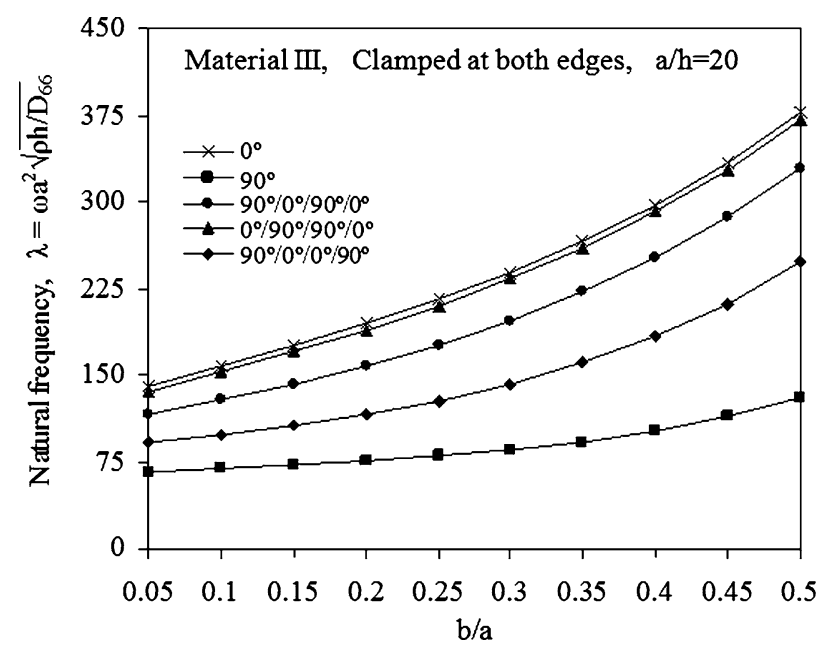

Fig. 4 Effect of hole radius on fundamental natural frequencies of laminated polar orthotropic annular plates

studies are also presented. In all the results presented here, the orientations of the fibers in the layers are identified either as $0^{\circ}$ or $90^{\circ}$, depending upon whether the layer is reinforced radially or circumferentially. The material properties along the principal directions are assumed to be the same in all the layers.

Free vibration frequencies of clamped isotropic circular plate are shown in Table 1. It can be seen from the results that converged results are obtained with 10-12 terms of the Chebyshev series approximation. Comparisons between the present results and those of the existing results based on the classical plate theory, three-dimensional plate theory and first-order shear deformation theory are made. Table 2 shows the fundamental natural frequencies of clamped isotropic circular plate which are

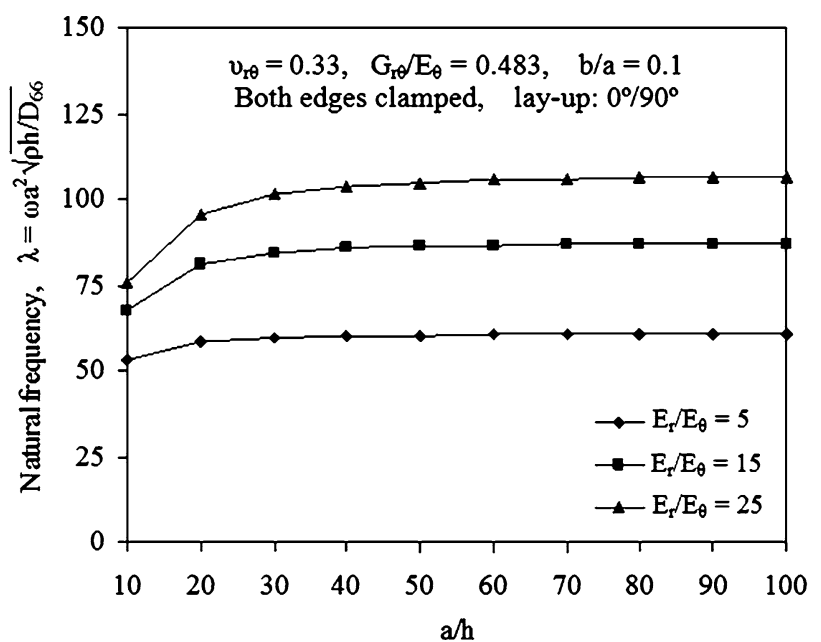

Fig. 5 Effect of orthotropy ratio on fundamental natural frequencies of laminated polar orthotropic annular plates

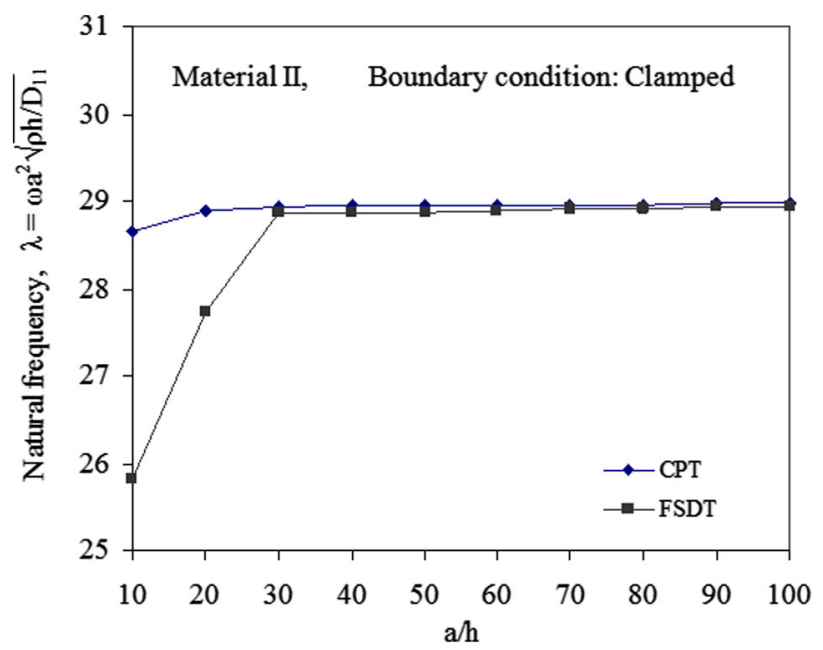

Fig. 6 Effect of shear deformation on fundamental natural frequencies of circular plates

in good agreement with the results obtained by Lin and Tseng (1998).

Good agreement between the present results and those of Lin and Tseng (1998) and Han and Liew (1999) for isotropic annular plates clamped at both edges is also seen in Table 3

\section{Parametric study}

Free vibration analysis has been carried out on orthotropic circular and annular plates. Material properties of specimens used in this study as obtained from literature (Lin and Tseng 1998) are as given below.

Material I: $E_{\theta} / E_{r}=5, G_{r \theta} / E_{r}=0.35, G_{r z} / E_{r}=0.292$, $G_{\theta z} / E_{r}=0.292, v_{\theta r}=0.3, \rho=1.0$. 
Table 4 Fundamental frequencies of polar orthotropic laminated circular plates composed of different materials; $\lambda=\omega a^{2} \sqrt{\rho h / D_{11}}$

\begin{tabular}{lrllllc}
\hline BC & $a / h$ & III & II & III/II/III/II & III/II/II/III & II/III/III/II \\
\hline Clamped & 10 & 26.248 & 13.404 & 15.226 & 21.132 & 13.456 \\
& 20 & 27.735 & 13.867 & 15.869 & 21.789 & 14.189 \\
& 50 & 28.867 & 14.003 & 16.071 & 21.985 & 14.381 \\
Simply supported & 100 & 28.940 & 14.031 & 16.100 & 22.022 & 14.414 \\
& 10 & 21.644 & 8.392 & 10.522 & 15.910 & 8.689 \\
& 20 & 22.690 & 8.512 & 10.714 & 16.182 & 8.873 \\
& 50 & 23.011 & 8.542 & 10.789 & 16.261 & 8.936 \\
& 100 & 23.058 & 8.548 & 10.798 & 16.268 & 8.944 \\
\hline
\end{tabular}

Table 5 Fundamental frequencies of polar orthotropic laminated annular plates composed of different materials; $\lambda=\omega a^{2} \sqrt{\rho h / D_{11}}$

\begin{tabular}{|c|c|c|c|c|c|c|c|}
\hline $\mathrm{BC}$ & $b / a$ & $a / h$ & III & II & III/II/III/II & III/II/II/III & II/III/III/II \\
\hline \multirow[t]{8}{*}{$\mathrm{C}-\mathrm{C}$} & \multirow[t]{4}{*}{0.1} & 10 & 46.409 & 28.146 & 30.287 & 41.634 & 26.921 \\
\hline & & 20 & 55.849 & 31.223 & 34.113 & 45.553 & 31.220 \\
\hline & & 50 & 60.127 & 32.300 & 35.464 & 46.937 & 32.864 \\
\hline & & 100 & 60.712 & 32.453 & 35.678 & 47.125 & 33.111 \\
\hline & \multirow[t]{4}{*}{0.5} & 10 & 91.516 & 71.796 & 71.319 & 89.052 & 65.952 \\
\hline & & 20 & 105.339 & 85.002 & 83.017 & 96.991 & 82.563 \\
\hline & & 50 & 110.485 & 90.203 & 87.437 & 99.602 & 89.984 \\
\hline & & 100 & 111.282 & 91.021 & 88.147 & 100.015 & 91.211 \\
\hline \multirow[t]{8}{*}{$S^{\text {in }}-C^{\text {out }}$} & \multirow[t]{4}{*}{0.1} & 10 & 47.388 & 26.034 & 28.387 & 47.629 & 25.271 \\
\hline & & 20 & 55.840 & 28.130 & 30.575 & 47.896 & 28.867 \\
\hline & & 50 & 57.619 & 28.867 & 31.037 & 48.041 & 29.196 \\
\hline & & 100 & 63.231 & 28.915 & 31.376 & 48.337 & 29.482 \\
\hline & \multirow[t]{4}{*}{0.5} & 10 & 83.800 & 62.683 & 62.907 & 78.015 & 58.752 \\
\hline & & 20 & 93.823 & 71.031 & 70.499 & 83.131 & 69.741 \\
\hline & & 50 & 97.312 & 74.023 & 73.166 & 84.758 & 74.084 \\
\hline & & 100 & 97.823 & 74.473 & 73.561 & 84.972 & 74.785 \\
\hline \multirow[t]{8}{*}{$C^{\text {in }}-S^{\text {out }}$} & \multirow[t]{4}{*}{0.1} & 10 & 39.467 & 20.471 & 23.219 & 33.171 & 19.972 \\
\hline & & 20 & 46.359 & 22.193 & 25.612 & 35.860 & 22.443 \\
\hline & & 50 & 49.183 & 22.777 & 26.477 & 36.788 & 23.370 \\
\hline & & 100 & 49.727 & 22.877 & 26.594 & 36.948 & 23.515 \\
\hline & \multirow[t]{4}{*}{0.5} & 10 & 73.741 & 53.467 & 54.137 & 67.040 & 50.539 \\
\hline & & 20 & 81.649 & 59.665 & 59.911 & 70.941 & 58.813 \\
\hline & & 50 & 84.394 & 61.839 & 61.898 & 72.168 & 61.981 \\
\hline & & 100 & 84.818 & 62.160 & 62.197 & 72.357 & 62.475 \\
\hline \multirow[t]{8}{*}{ S-S } & \multirow[t]{4}{*}{0.1} & 10 & 40.403 & 18.575 & 21.320 & 36.054 & 18.432 \\
\hline & & 20 & 46.092 & 19.561 & 22.055 & 38.258 & 19.868 \\
\hline & & 50 & 48.235 & 19.764 & 22.062 & 37.456 & 20.372 \\
\hline & & 100 & 49.758 & 19.765 & 22.205 & 37.739 & 20.338 \\
\hline & \multirow[t]{4}{*}{0.5} & 10 & 66.860 & 44.220 & 46.299 & 57.241 & 42.969 \\
\hline & & 20 & 72.074 & 46.978 & 49.242 & 59.328 & 46.906 \\
\hline & & 50 & 73.801 & 47.847 & 50.175 & 59.954 & 48.213 \\
\hline & & 100 & 74.043 & 47.973 & 50.315 & 60.051 & 48.410 \\
\hline
\end{tabular}

Material II: $\quad E_{\theta} / E_{r}=50, \quad G_{r \theta} / E_{r}=0.6613, \quad G_{r z} /$ $E_{r}=0.5511, G_{\theta z} / E_{r}=0.5511, v_{\theta r}=0.26, \rho=1.0$.

Material III (ultra-high-modulus graphite epoxy): $E_{r}=310 \times 10^{3} \mathrm{~N} / \mathrm{mm}^{2}, E_{\theta}=6.2 \times 10^{3} \mathrm{~N} / \mathrm{mm}^{2}, G_{r \theta}=$ $4.1 \times 10^{3} \mathrm{~N} / \mathrm{mm}^{2}, v_{r \theta}=0.26, \rho=1.613 \times 10^{3} \mathrm{~kg} / \mathrm{m}^{3}$.
In all the parametric studies reported herein, a 12-term solution is adopted hereafter, in computation of the free vibration response of different plates.

The results of parametric study to know the effect of the number of layers on the free vibration frequencies of a 
Table 6 Fundamental natural frequencies of polar orthotropic laminated circular plates: effect of fiber orientation; material III; $\lambda=\omega a^{2} \sqrt{\rho h / D_{66}}$
Table 7 Fundamental natural frequencies of polar orthotropic laminated annular plates: effect of fiber orientation; material III; $\lambda=\omega a^{2} \sqrt{\rho h / D_{66}}$

\begin{tabular}{lrlllll}
\hline $\mathrm{BC}$ & \multicolumn{1}{l}{ a/h } & \multicolumn{1}{l}{$0^{\circ}$} & $90^{\circ}$ & $90^{\circ} / 0^{\circ} / 90^{\circ} / 0^{\circ}$ & $0^{\circ} / 90^{\circ} / 90^{\circ} / 0^{\circ}$ & $90^{\circ} / 0^{\circ} / 0^{\circ} / 90^{\circ}$ \\
\hline Clamped & 10 & 48.552 & 32.793 & 49.549 & 45.539 & 41.959 \\
& 20 & 56.622 & 34.868 & 57.553 & 51.420 & 46.584 \\
& 50 & 64.415 & 35.522 & 61.475 & 52.646 & 48.173 \\
& 100 & 71.887 & 35.619 & 67.681 & 60.335 & 48.416 \\
Simply supported & 10 & 26.726 & 6.482 & 25.819 & 10.867 & 27.735 \\
& 20 & 27.735 & 9.950 & 26.726 & 12.598 & 28.867 \\
& 50 & 28.329 & 19.611 & 26.547 & 21.320 & 29.437 \\
& 100 & 28.867 & 22.880 & 26.130 & 28.860 & 30.151 \\
\hline
\end{tabular}

\begin{tabular}{|c|c|c|c|c|c|c|c|}
\hline $\mathrm{BC}$ & $b / a$ & $a / h$ & $0^{\circ}$ & $90^{\circ}$ & $90^{\circ} / 0^{\circ} / 90^{\circ} / 0^{\circ}$ & $0^{\circ} / 90^{\circ} / 90^{\circ} / 0^{\circ}$ & $90^{\circ} / 0^{\circ} / 0^{\circ} / 90^{\circ}$ \\
\hline \multirow[t]{8}{*}{$\mathrm{C}-\mathrm{C}$} & \multirow[t]{4}{*}{0.1} & 10 & 100.321 & 59.215 & 90.759 & 98.966 & 76.628 \\
\hline & & 20 & 157.582 & 69.404 & 128.809 & 152.979 & 97.916 \\
\hline & & 50 & 207.345 & 73.185 & 153.266 & 197.449 & 108.503 \\
\hline & & 100 & 219.159 & 74.597 & 158.034 & 207.613 & 110.397 \\
\hline & \multirow[t]{4}{*}{0.5} & 10 & 208.288 & 115.794 & 198.968 & 207.256 & 175.899 \\
\hline & & 20 & 377.587 & 130.811 & 329.368 & 371.544 & 247.840 \\
\hline & & 50 & 629.316 & 136.171 & 459.363 & 602.475 & 290.864 \\
\hline & & 100 & 727.778 & 136.999 & 493.563 & 686.964 & 298.940 \\
\hline \multirow[t]{8}{*}{$S^{\text {in }}-C^{\text {out }}$} & \multirow[t]{4}{*}{0.1} & 10 & 99.800 & 59.496 & 89.550 & 98.342 & 74.680 \\
\hline & & 20 & 152.127 & 69.673 & 122.840 & 147.313 & 92.489 \\
\hline & & 50 & 191.530 & 74.247 & 141.676 & 182.331 & 100.316 \\
\hline & & 100 & 200.080 & 75.701 & 145.156 & 189.694 & 101.529 \\
\hline & \multirow[t]{4}{*}{0.5} & 10 & 203.615 & 105.514 & 191.741 & 202.154 & 163.539 \\
\hline & & 20 & 355.177 & 116.247 & 301.101 & 347.776 & 216.777 \\
\hline & & 50 & 544.734 & 119.883 & 391.840 & 519.034 & 243.975 \\
\hline & & 100 & 606.004 & 120.429 & 412.638 & 571.102 & 248.759 \\
\hline \multirow[t]{8}{*}{$C^{\text {in }}-S^{\text {out }}$} & \multirow[t]{4}{*}{0.1} & 10 & 74.124 & 49.962 & 67.450 & 73.107 & 58.035 \\
\hline & & 20 & 107.670 & 57.792 & 89.694 & 104.313 & 70.728 \\
\hline & & 50 & 130.732 & 61.233 & 98.010 & 124.902 & 76.673 \\
\hline & & 100 & 135.444 & 61.244 & 104.507 & 129.024 & 77.732 \\
\hline & \multirow[t]{4}{*}{0.5} & 10 & 184.427 & 92.648 & 170.325 & 182.361 & 141.251 \\
\hline & & 20 & 307.002 & 101.113 & 255.906 & 299.610 & 181.071 \\
\hline & & 50 & 449.466 & 103.975 & 321.611 & 427.412 & 200.401 \\
\hline & & 100 & 491.889 & 104.404 & 335.842 & 463.340 & 203.700 \\
\hline \multirow[t]{8}{*}{ S-S } & \multirow[t]{4}{*}{0.1} & 10 & 73.821 & 50.144 & 66.328 & 72.490 & 55.971 \\
\hline & & 20 & 100.055 & 58.261 & 83.888 & 96.673 & 65.938 \\
\hline & & 50 & 114.123 & 61.061 & 92.253 & 109.304 & 69.572 \\
\hline & & 100 & 116.713 & 61.221 & 93.658 & 111.601 & 69.843 \\
\hline & \multirow[t]{4}{*}{0.5} & 10 & 184.302 & 83.565 & 166.689 & 181.608 & 127.837 \\
\hline & & 20 & 284.440 & 89.122 & 229.536 & 274.617 & 150.414 \\
\hline & & 50 & 362.666 & 90.871 & 265.092 & 342.997 & 159.272 \\
\hline & & 100 & 379.978 & 91.135 & 271.662 & 357.530 & 160.664 \\
\hline
\end{tabular}

laminated annular plate with both the edges clamped are presented in Fig. 2. Figure 3 presents the results of a study conducted to study the effect of boundary conditions on free vibration frequencies of a laminated polar orthotropic annular plate. Effect of the size of the hole on the fundamental frequency of annular plates clamped at both edges is shown in Fig. 4. 
Figure 5 shows the results of a study conducted to know the effect of orthotropy ratio on the free vibration frequencies of a two-layered asymmetric cross-ply annular plate with both the edges clamped.

A comparison of the natural frequencies calculated from the present shear deformation theory with those predicted by CPT is presented in Fig. 6. It can be observed that the effect of shear deformation is to decrease the free vibration frequencies in case of thick plates.

Fundamental natural frequencies of polar orthotropic laminated circular plates with clamped and simply supported boundary conditions are listed in Table 4. Results show that natural frequencies are influenced by stacking sequence and the order of the magnitude of the fundamental frequency for the five different laminates. For annular plates, the effects of stacking sequence on natural frequencies when the inner and outer edges are either clamped or simply supported are illustrated in Table 5 and are similar to those for circular plates.

Results of the fundamental frequency of several polar orthotropic laminated circular plates with clamped or simply supported boundary conditions are shown in Table 6. The ultra-high-modulus graphite epoxy composites are used in the examples. They reveal that among these different stacking sequences, the smallest natural frequency occurs when the plate is composed of laminae in which fibers are oriented in circumferential direction only. It seems to be reasonable, since the displacement and curvature of the first vibration mode of the plates are varied in the radial direction only. Hence, the laminated plate having higher stiffness in the radial direction would produce higher natural frequency and vice versa. Because the fibers are placed along circumferential direction in this laminate,

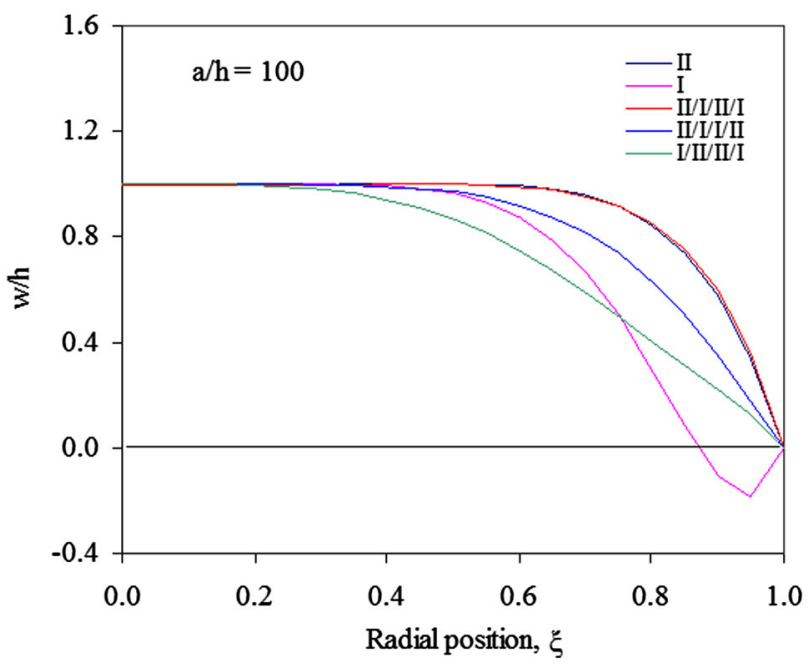

Fig. 7 Fundamental mode shapes for laminated polar orthotropic clamped circular plates the stiffness in the radial direction is smaller than any other laminates.

Fundamental frequencies of $\mathrm{C}-\mathrm{C}, \mathrm{S}^{\mathrm{a}}-\mathrm{C}, \mathrm{C}^{\mathrm{a}}-\mathrm{S}$ and $\mathrm{S}-\mathrm{S}$ polar orthotropic laminated annular plates listed in Table 7 show that the order of the magnitude of the fundamental frequency for these five laminates is $\left(0^{\circ}\right)>\left(0^{\circ} / 90^{\circ} / 190^{\circ} \%\right.$ $\left.0^{\circ}\right)>\left(90^{\circ} / 0^{\circ} / 90^{\circ} / 0^{\circ}\right)>\left(90^{\circ} / 0^{\circ} / 0^{\circ} / 90^{\circ}\right)>\left(90^{\circ}\right)$. The same behavior has been found for laminated plates given by Lin and Tseng (1998). Typical axisymmetric mode shapes (torsionless) corresponding to fundamental natural frequencies for the laminated circular and annular plates with different boundary conditions, showing the effect of stacking sequences, are plotted in Figs. 7, 8, 9, 10, 11 and 12.

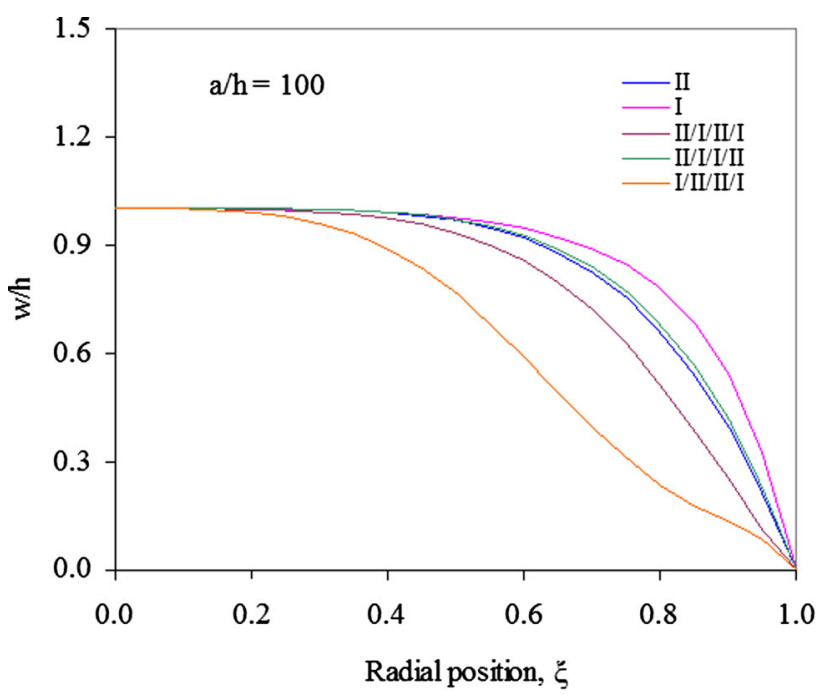

Fig. 8 Fundamental mode shapes for laminated polar orthotropic simply supported circular plates

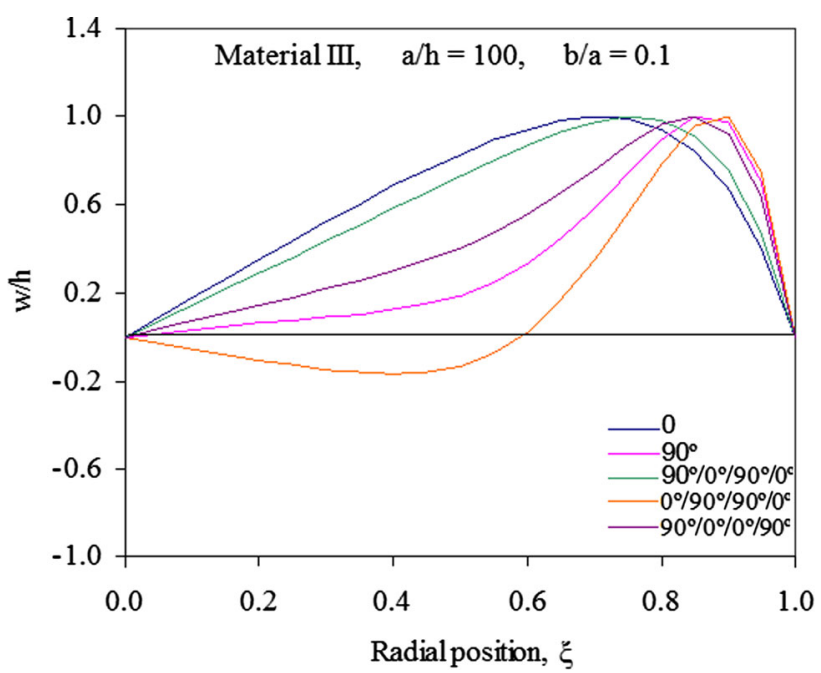

Fig. 9 Fundamental mode shapes for laminated polar orthotropic C$\mathrm{C}$ annular plates 


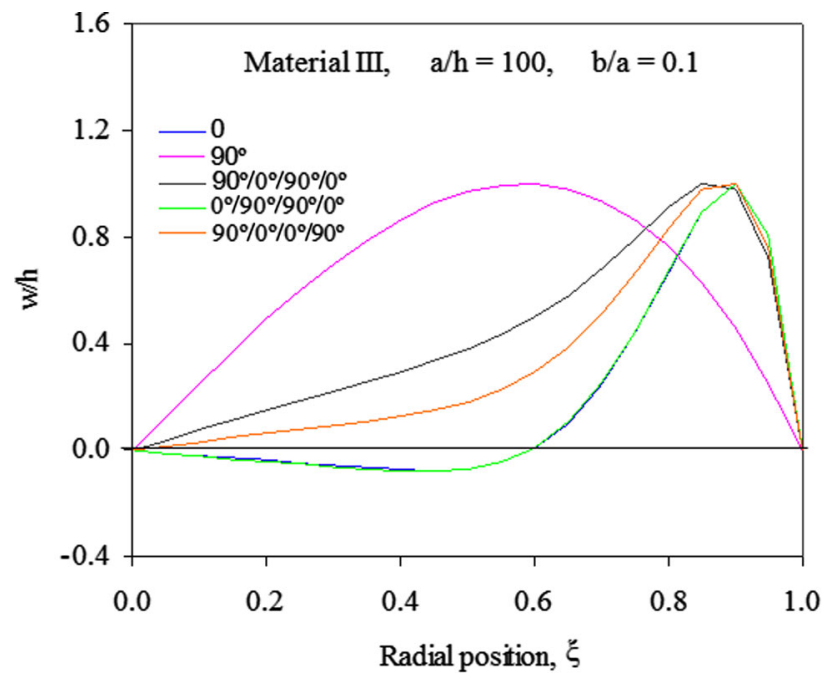

Fig. 10 Fundamental mode shapes for laminated polar orthotropic $\mathrm{S}^{\mathrm{a}}-\mathrm{C}$ annular plates

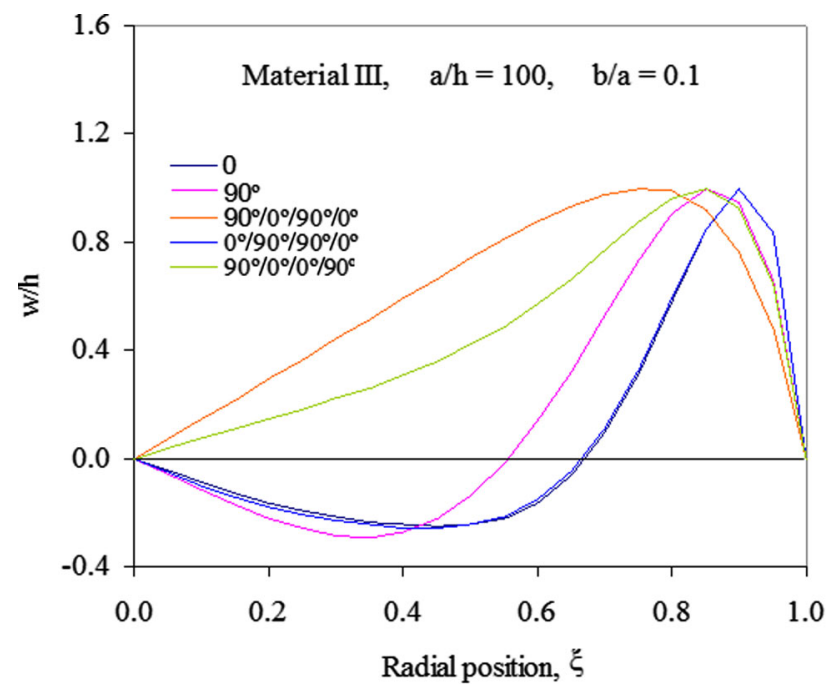

Fig. 11 Fundamental mode shapes for laminated polar orthotropic $\mathrm{C}^{\mathrm{a}}-\mathrm{S}$ annular Plates

\section{Conclusions}

Free vibration characteristics of composite circular and annular plates were studied in detail, with formulation based on a first-order shear deformation theory and a solution methodology employing the Chebyshev collocation technique. Convergence tests were conducted for the Chebyshev collocation technique and it can be seen that there is excellent convergence even when we take four or six terms in the series for the problem considered. Further, numerical results have aided to conclude that

- The solution method, based on collocating the equations of motion at Chebyshev zeroes as proposed herein, developed systematically in polar co-ordinates,

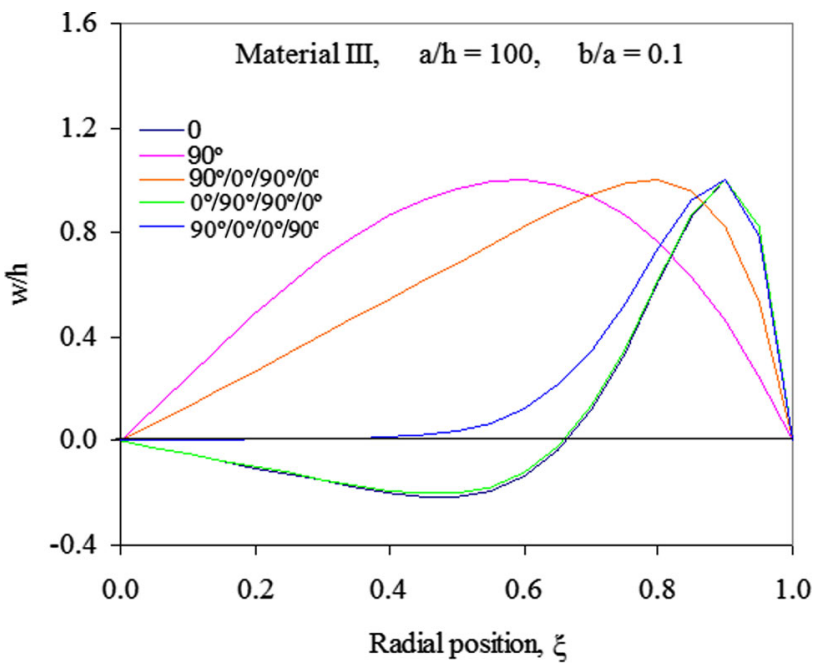

Fig. 12 Fundamental mode shapes for laminated polar orthotropic S$S$ annular plates

is reliable and effective for finding natural frequencies and mode shapes of polar orthotropic circular and annular plates. The fundamental frequency of polar orthotropic laminated annular plates increases with an increase in number of layers, hole size and orthotropy ratio. Fundamental frequencies are higher for clamped boundary conditions.

- Transverse shear effects are more significant for polar orthotropic laminated plates than isotropic plates. Further, the transverse shear effects are negligible in case of thin plates.

- For polar orthotropic laminated circular and annular plates with clamped edges, the laminate stacked with all layers having fibers oriented along the radial direction has the highest fundamental frequency.

- Parametric studies conclude that free vibration frequencies are dependent not only on the radius to thickness ratio, but also on plate parameters such as the fiber orientation, lamination sequence, hole diameter and the boundary conditions.

Author contributions A. Powmya carried out the study under the guidance of MCN. MCN also participated in the sequence alignment and drafted the manuscript. Both authors read and approved the final manuscript.

Conflict of interest The authors declare that they have no competing interests.

Open Access This article is distributed under the terms of the Creative Commons Attribution 4.0 International License (http:// creativecommons.org/licenses/by/4.0/), which permits unrestricted use, distribution, and reproduction in any medium, provided you give appropriate credit to the original author(s) and the source, provide a 
link to the Creative Commons license, and indicate if changes were made.

\section{References}

Antia HM (2002) Numerical methods for scientists and engineers. Hindustan Book Agency, New Delhi

Carey GF, Finlayson BA (1974) Orthogonal collocation on finite elements. Chem Eng Sci 30:587-596

Ding HJ, Xu RQ (2000) Free axisymmetric vibration of laminated transversely isotropic annular plates. J Sound Vib 230(5): 1031-1044

Dumir PC, Gandhi ML, Nath Y (1984) Axisymmetric static and dynamic buckling of orthotropic shallow spherical caps with circular hole. Comput Struct 19(5/6):725-736

Dumir PC, Joshi S, Dube GP (2001) Geometrically nonlinear axisymmetric analysis of thick laminated annular plate using FSDT. Compos B 32:1-10

Han JB, Liew KM (1997) Analysis of moderately thick circular plates using differential quadrature method. J Eng Mech 123(12): $1247-1252$

Han JB, Liew KM (1999) Axisymmetric free vibration of thick annular plates. Int J Mech Sci 41(9):1089-1109

Haterbouch M, Benamar R (2005) Geometrically nonlinear free vibrations of simply supported isotropic thin circular plates. J Sound Vib 280(3-5):903-924

Hosseini-Hashemi SH, Akhavan H, Rokni Damavandi Taher H, Daemi N, Alibeigloo A (2010) Differential quadrature analysis of functionally graded circular and annular sector plates on elastic foundation. Mater Des 31(4):1871-1880

Liew KM, Liu FL (2000) Differential Quadrature method for vibration analysis of shear deformable annular sector plates. J Sound Vib 230(2):335-356

Liew KM, Yang B (1999) Three dimensional elasticity solutions for the free vibrations of circular plates: a polynomials-Ritz analysis. Comput Methods Appl Mech Eng 175(1-2):189-201
Liew KM, Yang B (2000) Elasticity solutions for free vibrations of annular plates from three dimensional analysis. Int J Solids Struct 37(52):7689-7702

Liew KM, Han J-B, Xiao ZM (1997) Vibration analysis of Circular Mindlin plates using the Differential quadrature method. J Sound Vib 205(5):617-630

Lin CC, Tseng CS (1998) Free vibration of polar orthotropic laminated circular and annular plates. J Sound Vib 209(5):797-810

Narasimhan MC (1992) Dynamic response of laminated orthotropic spherical shells. J Acoust Soc Am 91(5):2714-2720

Nath Y, Jain RK (1986) Nonlinear studies of orthotropic shallow spherical shells on elastic foundations. Int J Nonlinear Mech 21:447-458

Ravichandran V (1989) Some studies on the analysis of circular multilayer plates. M.Tech. Dissertation, Department of Applied Mechanics, IIT Madras, India

Selmane A, Lakis AA (1999) Natural frequencies of transverse vibrations of non-uniform circular and annular plates. J Sound Vib 220(2):225-249

Tornabene F, Viola E, Inman DJ (2009) 2-D differential quadrature solution for vibration analysis of functionally graded conical, cylindrical shell and annular plate structures. J Sound Vib 328(3):259-290

Villadsen JV, Stewart WE (1967) Solution of boundary-value problems by orthogonal collocation. Chem Eng Sci 22:1483-1501

Wu TY, Wang YY, Liu GR (2002) Free vibration analysis of circular plates using generalized differential quadrature rule. Comput Methods Appl Mech Eng 191(46):5365-5380

Xiang X, Guoyong J, Wanyou L, Zhigang L (2014) A numerical solution for vibration analysis of composite laminated conical, cylindrical shell and annular plate structures. Compos Struct 111:20-30

Zhou D, Au FTK, Cheung YK, Lo SH (2003) Three dimensional vibration analysis of circular and annular plates via the Chebyshev-Ritz method. Int J Solids Struct 40(12):3089-3105 